\title{
Age determination of the Mongolian wild ass (Equus hemionus Pallas, 1775) by the dentition patterns and annual lines in the tooth cementum
}

\author{
Davaa Lkhagvasuren ${ }^{1, *}$, Hermann Ansorge ${ }^{2}$, Ravchig Samiya ${ }^{1}$, Renate Schafberg ${ }^{3}$, Anne Stubbe ${ }^{4}$ and \\ Michael Stubbe ${ }^{4}$ \\ ${ }^{1}$ Department of Ecology, School of Biology and Biotechnology, National University of Mongolia, PO-Box 377 \\ Ulaanbaatar 210646 \\ ${ }^{2}$ Senckenberg Museum of Natural History, Goerlitz, PF 300154 D-02806 Goerlitz, Germany \\ ${ }^{3}$ Institut für Agrar- und Ernährungswissenschaften, Professur fuer Tierzucht, MLU, Museum für Haustierkunde, \\ Julius Kuehn-ZNS der MLU, Domplatz, 4, D-06099 Halle/Saale, Germany \\ ${ }^{4}$ Institute of Zoology, Martin-Luther University of Halle Wittenberg, Domplatz 4, D-06099 Halle/Saale, Germany \\ *Correspondent: Lkhagvasuren@num.edu.mn
}

\begin{abstract}
Based on 440 skulls recently collected from two areas of the wild ass population in Mongolia, the time course of tooth eruption and replacement was investigated. The dentition pattern allows identification of age up to five years. We also conclude that annual lines in the tooth cementum can be used to determine the age in years for wild asses older than five years after longitudinal tooth sections were made with a lowspeed precision saw. The first upper incisor proved to be most suitable for age determination, although the starting time of cement deposition is different between the labial and lingual sides of the tooth. The accurate age of the wild ass can be determined from the number of annual lines and the time before the first formation of the cementum at the respective side of the tooth.
\end{abstract}

Keywords: age determination, annual lines, dentition, Equus hemionus, Mongolia, Mongolian wild ass, tooth cementum

\section{INTRODUCTION}

The Mongolian wild ass or Khulan (in Mongolian) Equus hemionus hemionus Pallas, 1775 is one of the flagship species that occurs in extreme ecosystems of the World (Kaczensky and Walzer, 2008). Its population is still decreasing year by year due to direct impact of illegal hunting, habitat degradation and limited water access in Mongolia (Feh et al., 2002; Stubbe et al., 2005; Clark et al., 2006; Kaczensky et al., 2006; Wingard and Zahler, 2006; Stubbe et al., 2007; Kaczensky and Walzer, 2008; Moehlman et al., 2008). However, almost $80 \%$ of the total population of the Mongolian wild ass in the World is found in Mongolia (Feh et al., 2002), hence the Mongolian population is critical to the preservation of the species (Reading et al., 2001). For long-term conservation of the Mongolian wild ass, specific knowledge on its biology and ecology is essential, including the influ- ence of poaching on the population size and population structure. With respect to population analysis, the determination of the accurate age is important baseline data. Poached animals can be used as a sample for age determination of the Mongolian wild ass population.

Several methods have been developed to assess the true age of dead individuals of many species (Sergeant, 1967; Morris, 1972; Harris, 1978; Habermehl, 1985; Lüps et al., 1987). In the present study, two most accurate methods were chosen: 1.) dentition pattern and 2.) annual lines in the tooth cementum. The eruption and replacement of the teeth has also been used for the age determination of several wild-living equids: mountain zebra Equus zebra zebra, Hartmann zebra Equus zebra hartmannae and plains zebra Equus burchellii (Erz, 1964; Klingel and Klingel, 1966; Joubert, 1972; Penzhorn, 1982), as well as two domestic species of the Equidae closely related to the Mongolian wild ass: the domestic donkey Equus asinus (Svendsen, 1997) and the domestic horse Equus caballus 


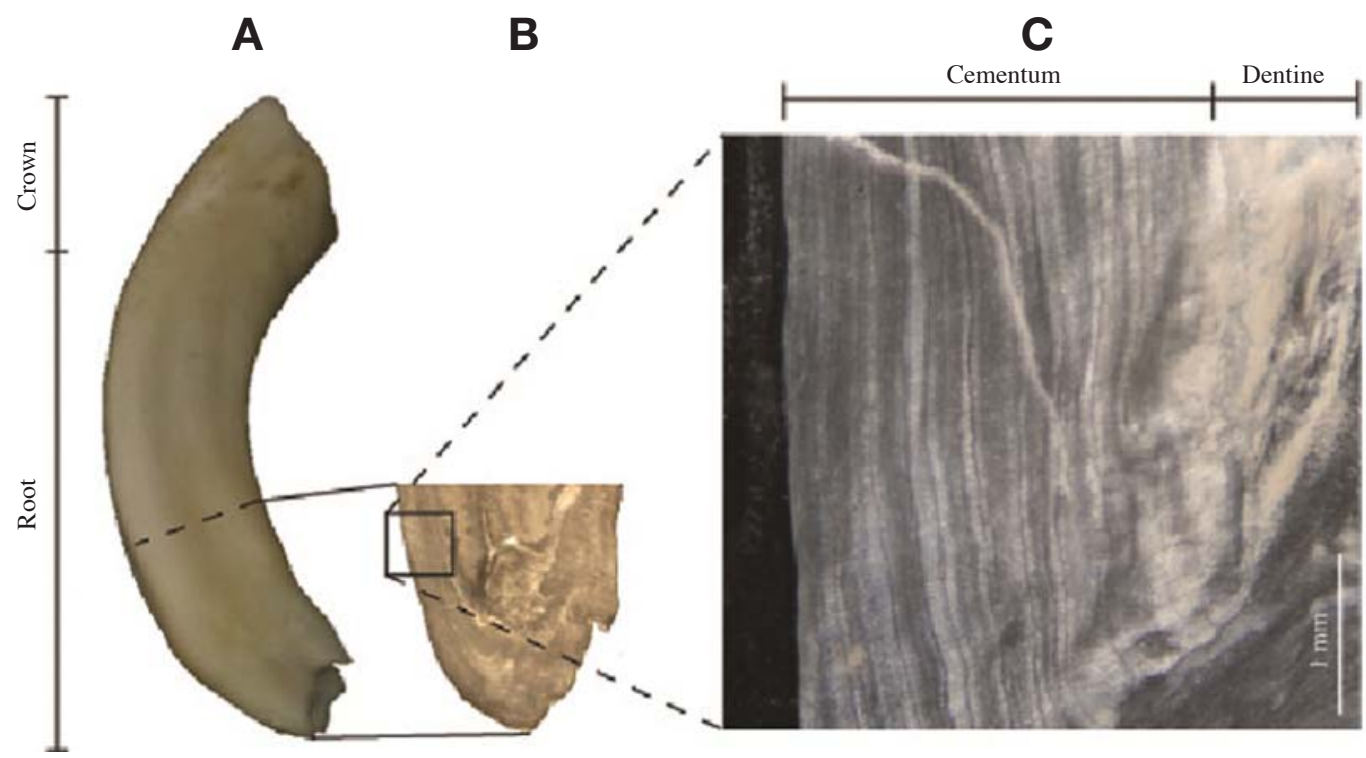

Fig. 1. First lower incisor (A) and its longitudinal section(B) with annual lines (C).

(Habermehl, 1985). Nevertheless, no usable information exists regarding the dentition of the wild asses (Orlov, 1961; Ansorge et al., 2007). Only Orlov (1961) gives some short remarks, and Heptner et al. (1966) described the tooth replacement of the Mongolian wild ass incorrectly by "die Milchzaehne werden mit dem 4. Jahr durch bleibende ersetzt" ("milk dentition is replaced by the permanent teeth as of the fourth year"). Nevertheless, comparison of the well known dentition of the domestic equids and the zebras with the collected skulls of the Mongolian wild ass is used to clarify the dentition of the species.

The accurate age of an older animal can be determined by the incremental cementum lines of tooth sections (Laws, 1962; Morris, 1972; Grue and Jensen, 1979; Klevezal, 1996). This method has been used successfully to estimate the age of mountain zebra Equus zebra zebra and plains zebra Equus burchelli (Smuts, 1974; Penzhorn, 1982). Klevezal and Kleinenberg (1967) mentioned "regular, probably annular, layers in the cementum and secondary dentin" of Equus hemionus, but did not consider the features for age determination.

The objective of this study was to evaluate a method of accurate age determination for Mongolian wild ass using teeth eruption and replacement, as well as by annual lines in the dental cementum.

\section{Materials ANd Methods}

The study is based on 440 skulls of the Mongolian wild ass collected between 2002 and 2010 mainly from two regions of southern Mongolia (Stubbe et al., 2005; 2007). Of these, 376 skulls (177우, 147 ð 52 unknown) origi- nated from the southern Gobi (mostly from the Bordzongijn Gobi) and 64 (20우, $24 \sigma^{7}, 20$ unknown) from the south-western Gobi (Dzungarian Gobi).

Skulls of asses found dead were often preserved in a mummified condition covered by skin. This made it possible to estimate the season of death by the different summer and winter coat.

The sequence of eruption and replacement of the teeth could be evaluated by comparing different development of the teeth of 127 individuals showing unfinished dentition. The time of the consecutive appearances of the teeth were assessed, including further comparative investigations on related equid species like zebras, domestic horse and donkey (Erz, 1964; Klingel and Klingel, 1966; Joubert, 1972; Penzhorn, 1982; Habermehl, 1985; Svendsen, 1997).

Based on the periodic growth, there are annual lines in the cementum of the tooth root, which can be used for determining the age in years for many mammals. In order to assess if such lines exist in the Mongolian wild ass and to check which kind of teeth provide the most prominent lines, a total of 455 permanent teeth from 314 individuals were cut using a standard technique with a diamond wheel of a low-speed precision saw (Buehler IsoMet $^{\circledR}$ 1000) (Johnston and Watt, 1980; Driscoll et al., 1985; Ansorge, 1995). Tooth roots were longitudinally sectioned by a diamond wheel of a low-speed precision saw without any pre-treatment. Generally, three cuts of every tooth were mounted on a slide with Histofluid made by Paul Marienfeld GmbH - a water-clear adhesive of acrylic resins dissolved in xylene. The unstained sections show annual lines - if present - under reflected light by lateral illumination (Fig. 1) (Ansorge et al., 2007; Lkha- 


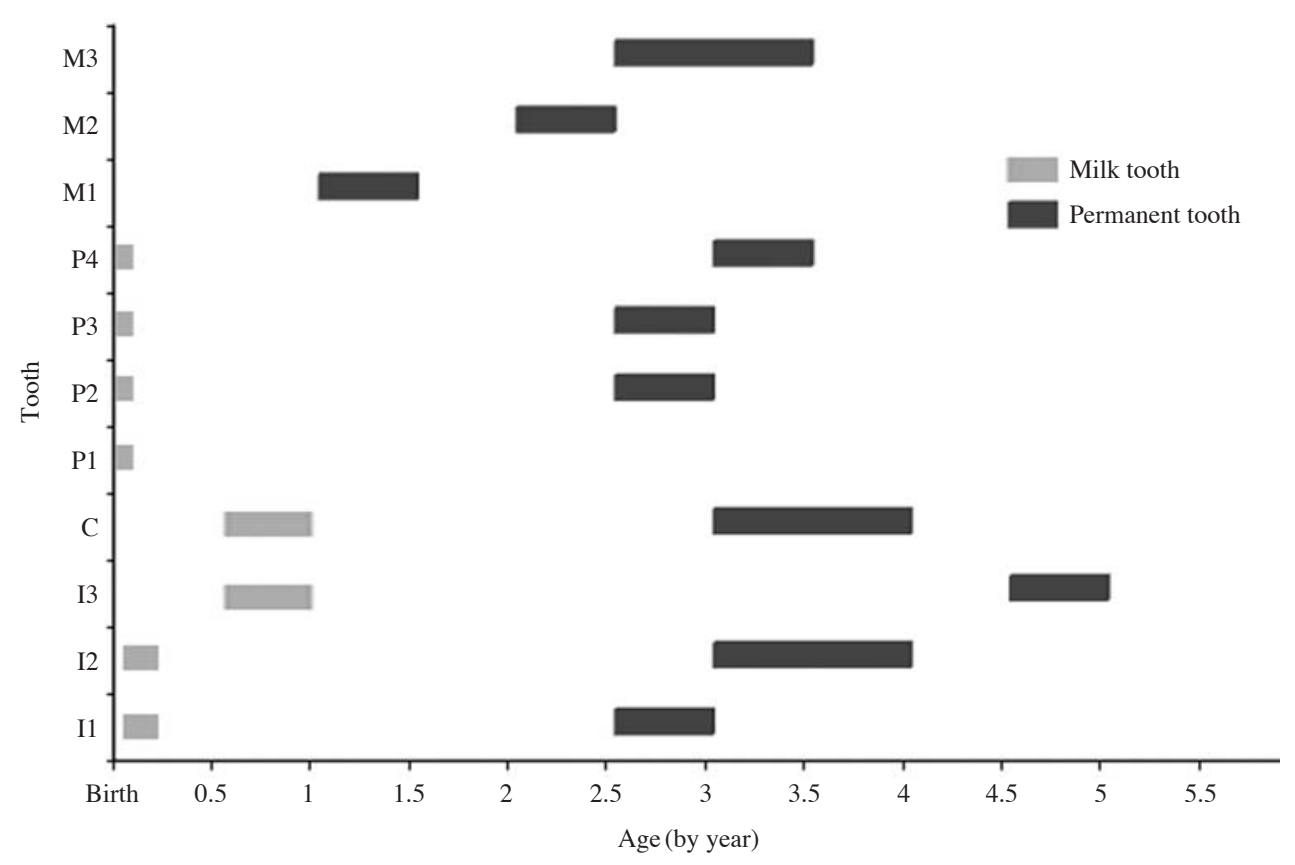

Fig. 2. Times of eruption and replacement of the teeth in the Mongolian wild ass.

gvasuren et al., 2009).

Time of the first development of tooth cementum and of the first incremental line were taken from skulls of known age, which was determined by their sequence of tooth replacement. The season of death could be estimated for 226 cases by the winter or summer coat on the skull.

\section{RESUlts}

As a first result of examination of the extensive material of Mongolian wild ass, a basic outline of tooth development can be given for the species (Fig. 2).

\section{Deciduous dentition}

Although our sample of skulls did not include newborn animals, the eruption of all four deciduous premolars and the deciduous canine can be assumed at the time of birth because the youngest specimens of our material $(<3$ weeks) already show these teeth. However, the first small premolar and the canine mostly do not appear but exist below the gum line (Fig. 3). In some cases, the first premolar is totally missing from the tooth row. Shortly after birth the two inner incisors appear to erupt nearly simultaneously. The corner incisor follows after about half a year.

The time between eruption of these deciduous teeth is relatively short. This makes it possible to determine the age of a Mongolian wild ass in months up to an age of one year.

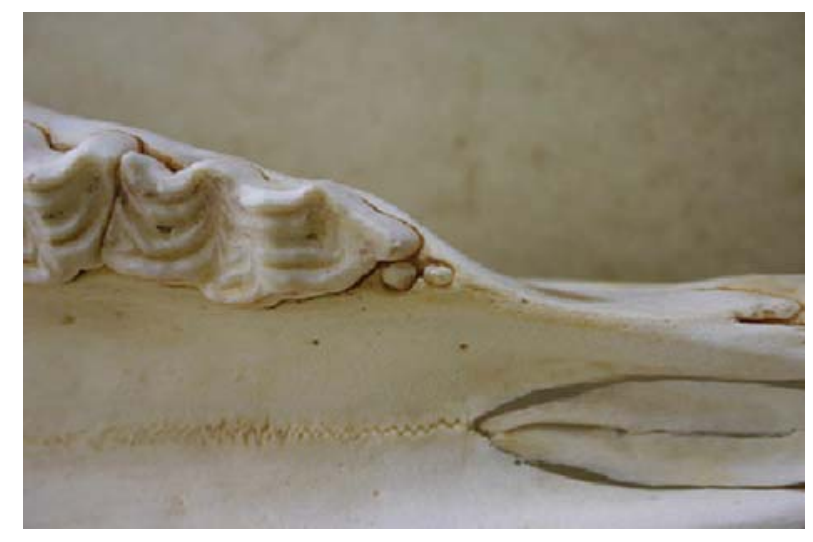

Fig. 3. Occurrence of deciduous and permanent first premolars in the Mongolian wild ass skull.

The deciduous dental formula of the Mongolian wild ass is the same as in the other equid species: specially, a small canine may occur in females, which is not visible.

$$
\text { Male: } \frac{\operatorname{Id} 3 \mathrm{Cd} 1 \mathrm{Pd} 3(4)}{\operatorname{Id} 3 \mathrm{Cd} 1 \mathrm{Pd} 3(4)}=28(32)
$$

Female: $\frac{\operatorname{Id} 3 \mathrm{Cd} 0(1) \mathrm{Pd} 3(4)}{\operatorname{Id} 3 \mathrm{Cd} 0(1) \operatorname{Pd} 3(4)}=24(32)$

$(\mathrm{Id}=$ deciduous incisor, $\mathrm{Cd}=$ deciduous canine, $\mathrm{Pd}=$ deciduous premolar)

\section{Permanent dentition}

As the initial permanent tooth, the first premolar app- 
ears a few weeks after birth (Fig. 3), but sometimes does not cut through the gum or may be missing. The first molar erupts from the following spring to summer, and the second molar does the same one year later. The first incisor, the second and the third premolar erupt from the third summer to autumn. After that the canine, the last premolar and the last molar appear the fourth autumn to winter. Shortly after that, the second incisor erupts during the fourth winter to spring. More than one year later, the corner incisor replaces the respective milk tooth as the last permanent tooth at an age of about five years. Thus, using the chronology of permanent dentition, the age of the Mongolian wild ass can be determined up to five years of age.

Table 1. The time of deposition of cementum and annual line formation at the labial- and lingual side of the first incisor $\left(\mathrm{I}^{1}\right)$.

\begin{tabular}{lccccc}
\hline \multirow{2}{*}{ Age } & \multicolumn{2}{c}{ Cementum } & & \multicolumn{2}{c}{ First incremental line } \\
\cline { 2 - 3 } \cline { 5 - 6 } & $\begin{array}{c}\text { Labial side, } \\
\%\end{array}$ & $\begin{array}{c}\text { Lingual side } \\
\%\end{array}$ & & $\begin{array}{c}\text { Labial side, } \\
\%\end{array}$ & $\begin{array}{c}\text { Lingual side, } \\
\%\end{array}$ \\
\hline $3(\mathrm{n}=7)$ & 0 & 29 & & 0 & 29 \\
$3.5(\mathrm{n}=13)$ & 0 & 77 & & 0 & 77 \\
$4(\mathrm{n}=11)$ & 27 & 91 & & 0 & 91 \\
$4.5(\mathrm{n}=22)$ & 36 & 91 & & 9 & 91 \\
$5(\mathrm{n}=20)$ & 45 & 100 & & 20 & 100 \\
$6(\mathrm{n}=28)$ & 93 & 100 & & 89 & 100 \\
\hline
\end{tabular}
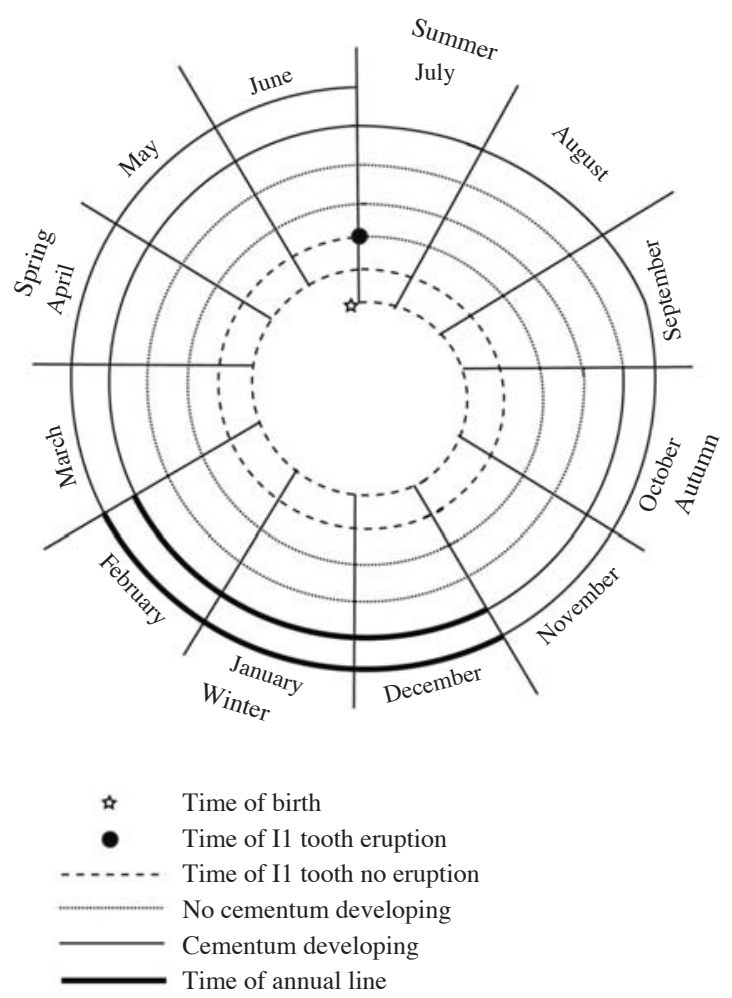

The respective permanent dental formula is:

Male: $\frac{\text { I } 3 \text { C } 1 \text { P } 4 \text { M } 3}{\text { I } 3 \text { C } 1 \text { P } 4 \text { M } 3}=44$

Female: $\frac{\text { I } 3 \text { C 0(1) P } 4 \text { M } 3}{\text { I } 3 \text { C 0(1) P } 4 \text { M } 3}=40(44)$

\section{Annual lines in the tooth cementum}

Incremental growth lines were found in every type of tooth of the Mongolian wild ass, except for the small first premolar. However, only the incisors, especially the first incisor of the upper skull, showed a clearly countable number of lines. Although the premolars and molars sometimes had well distinguishable lines, they were difficult to count.

In the first upper incisor, no cementum was recognizable at the time of eruption at an age of about 2.5 years. Half a year later, the deposition of cementum started at the lingual side of the incisor in two individuals that were checked. This continued, and at an age older than 4.5 years, every first upper incisor showed cementum at its lingual side (Table 1). The deposition of cementum showed a delay of two years at the labial side of this tooth.

Formation of the first annual line appeared at an age between three and a half years at the lingual side of the tooth (Table 1). Because the deposition of cementum start-
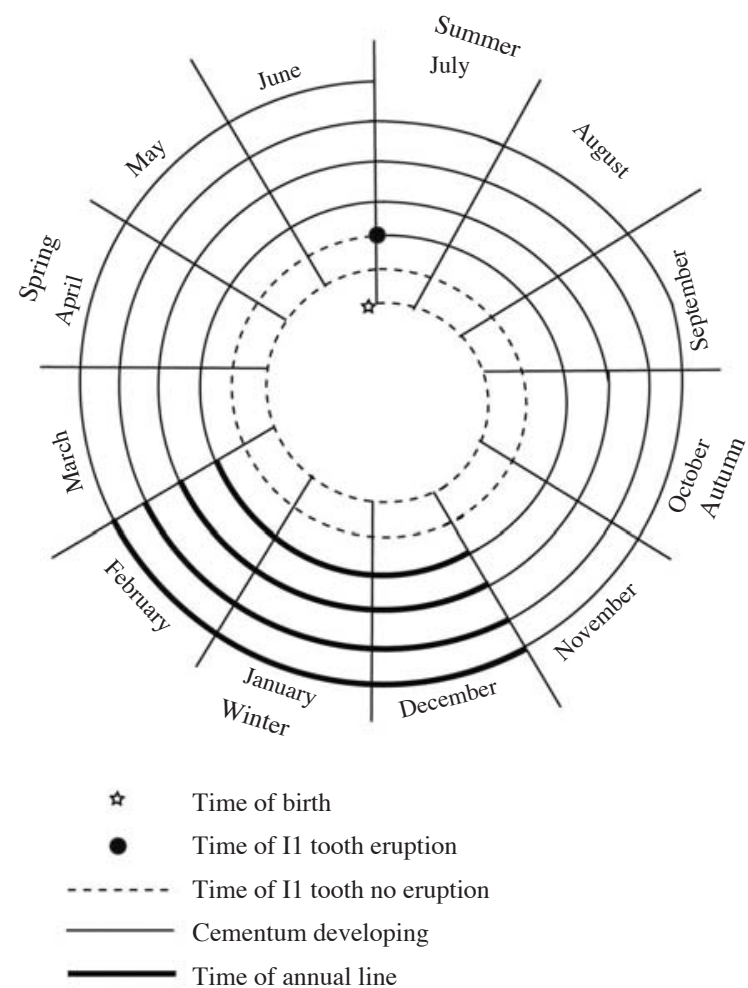

Fig. 4. The times of eruption, development of cementum and formation of the annual lines in the first upper incisor $\left(\mathrm{I}^{1}\right)$ at the labial $(\mathrm{left})$ and lingual side (right). 
ed later at this side, the labial side of the incisor showed the first line only at an age of five years and older.

Based on estimation of the season of death of the specimens, the formation of the incremental growth lines take place during winter. The relationship between time of birth, eruption of the tooth, development of cementum and appearance of annual lines is shown in Fig. 4. Thus, depending on the time of death, $\geq 2$ years have to be added to the number of lines at the lingual side of the tooth to get the age in years. At the labial side, four years had to be added to determine the age.

\section{Discussion}

"The ability to determine the absolute age of an animal is one of the most useful techniques available to any wildlife biologists" (Harris, 1978). The knowledge of exact ages of the individuals in a sample opens a window for further research in different areas including morphology, population ecology, conservation, reproduction biology or physiology, pathology and contamination. Among the diverse methods developed to acquire information on the age of dead individuals, most of them only distinguish between juveniles and adults or distinguish a few rough age classes (Morris, 1972; Harris, 1978; Habermehl, 1985; Lüps et al., 1987). This kind of age estimation, i.e., by tooth abrasion or general skull characteristics, does not normally provide enough information for calculating mortality and survival rates or developing population models (Habermehl, 1985). Therefore, this methodological study focused on more precise procedures of age determination using the dentition pattern and the annual lines in tooth cementum and neglecting less precise methods (Ansorge et al., 2007).

During the study, the sequence of dentition of the Mongolian wild ass was recorded for the first time. However, it appears that the replacement of deciduous teeth by permanent teeth is slightly prolonged in the Mongolian wild ass, although it is quite similar to the sequence in the domestic horse and the donkey (Habermehl, 1985; Svendson, 1997). The variation in the time of eruption of the single teeth is quite small which enables the correct age determination up to five years.

In the domestic horse and in the donkey, Habermehl (1985) and Svendson (1997) found only the permanent first premolar without any deciduous predecessor in agreement with the general opinion on the dentition pattern of equids. However, this has to be rejected. Because we studied macerated and cleaned skulls, we also recorded the small first deciduous premolar, which frequently does not cut through the gum and sometimes does not appear (Ansorge et al., 2007). A similar situation is described by Joubert (1972), who also found only the permanent first premolar in the Hartmann zebra, interpreted as the first deciduous premolar with no successor, as being a persisting milk tooth (Ansorge et al., 2007), perhaps based on the same confusion of the permanent and deciduous teeth. The phenomenon of a suppressed deciduous first premolar is also known from the carnivores where this tooth only appears as a rudimentary tooth bud and does not protrude through the gum (Ansorge, 1991).

The formation of annual incremental lines in the cementum of the tooth roots is well known from ungulates in general (Klevezal, 1996), as well as from several freeliving species of the Equidae, such as the mountain zebra, Burchell's zebra and the African wild ass (Smuts, 1974; Penzhorn, 1982). For the Mongolian wild ass, Klevezal and Kleinenberg (1967) noted distinct lines in the tooth cementum, but could not verify that these were annual lines. Our study confirms these lines to be annual through the use of a large number of specimens, especially in the cementum of the first upper incisor. Smuts (1974) and Penzhorn (1982) used the incisors of the zebra species for age determination, but Santiapillai (1999) determined the age of the African wild ass by sections of the molar cementum only. Ansorge et al. (2007) emphasized that in the Mongolian wild ass "only cheek teeth are suitable for checking cementum annuli, since the incisors close their pulp chambers only later." However, the present investigation demonstrates that the cementum of the incisors is deposited from the time of tooth eruption. Therefore it is possible to use incisors for age determination if the different intiation of deposition of the lingual and labial side of the tooth is taken into account. This phenomenon is found for the first time and only in the Asiatic wild ass (Morris, 1972; Klevezal, 1996), but likely exists in other ungulates too.

To conclude, determination of age of the Mongolian wild ass is possible by using the frequency of the dentition up to an age of five years. For older specimens, the number of annual lines in the tooth cementum can be counted and adjusted $(+2 \mathrm{y}$ for lingual side; $+4 \mathrm{y}$ for labial) for age determination.

\section{ACKNOWLedgements}

We are very grateful to Margit Hanelt (Görlitz), Diana Jeschke (Görlitz) and Roland Müller (Halle) for preparing and keeping all the wild ass skulls. Sincere thanks go to Bazartseren Boldgiv (Ulaanbaatar) for English revision. Also, this research is part of the MongolianGerman Biological Expeditions since 1962, No. 311 and all the contribution by the researchers of the expedition are greatly acknowledged. 


\section{REFERENCES}

Ansorge, H. 1991. Diphyodont dentition of first premolar in the red fox Vulpes vulpes (Linné, 1758). Zeitschrift fuer Saeugetierkunde 56:188-189.

Ansorge, H. 1995. Remarks on the age determination by growth lines in the mammalian skull. Wiss. Beitr. Univ. Halle. 1995:95-102 (in German).

Ansorge, H., A. Stubbe, N. Batsaijchan, R. Samiya and M. Stubbe. 2007. Assessment of the non metric skull characters and age determination in the Asiatic Wild Ass Equus hemionus - a methodological approach. Exploration into the Biological Resources of Mongolia 10:133-142.

Clark, E.L., J. Munkhbat, S. Dulamtseren, Bailie, J.E.M., N. Batsaijchan, R. Samiya and M. Stubbe. 2006. Mongolian Red List of Mammals. Ulaanbaatar.

Driscoll, K.M., G.S. Jones and F. Nichy. 1985. An efficient method by which to determine age of carnivores, using dentine rings. J. Zool., London 205:309-313.

Erz, W. 1964. Tooth eruption and replacement in Burchell's Zebra Equus burchelli Grau 1825. Arnolda 22:1-8.

Feh, C., N. Shah, M. Rowen, R. Reading and S.P. Goyal, 2002. Status and Action Plan for the Asiatic Wild Ass (Equus hemionus). 62-71.

Grue, H. and B. Jensen. 1979. Review of the formation of incremental lines in tooth cementum of terrestrial mammals. Danish Review of Game Biology 11(3):1-48.

Habermehl, K.H. 1985. Die Altersbestimmung beim Pferd. In: Habermehl, K.H. (ed.), Die Alterbestimung bei Hausund Labortieren. Paul Parey, Hamburg: 22-57.

Harris, S. 1978. Age determination in the red fox (Vulpes vulpes) - an evaluation of technique efficiencey as applied to a sample of suburban foxes. J. Zool., Lond. 184:91-117.

Heptner, V.G., A.A. Nasimovič and A.G. Bannikow. 1966. Band I: Paarhufer und Unpaarhufer. In: V.G. Heptner and N.P. Naumov. (eds), Die Säugetiere der Sowjetunion. Gustav Fischer, Jena, 939 pp (in German).

Johnston, D.H. and I.D. Watt. 1980. A rapid method for sectioning undecalcified carnivore teeth for aging. Worldwide Furbearer Conference Proceedings, August 3-11 1980, Frostburg, Maryland USA: 407-422.

Joubert, E. 1972. Tooth development and age determination in the Hartmann Zebra Equus zebra hartmannae. Madoquw 6:5-16.

Kaczensky, P., D.P. Sheehy, C. Walzer, D.E. Johnson, D. Lkhagvasuren and C.M. Sheehy. 2006. Room to Roam? The threat to khulan (wild ass) from human intrusion. Mongolian Discussion Papers, East Asia and Pacific Environment and Social Development Department. Washington, D.C.: World Bank.

Kaczensky, P. and C. Walzer. 2008. Der Asiatische Wildeselbedrohter Ueberlebenskuenstler in der Wueste Gobi. Zeitschrift des Koelner Zoos. 51(3):147-163.

Klevezal, G.A. 1996. Recording Structures of Mammals. A.A. Balkema, Moskow.

Klevezal, G.A. and S.E. Kleinenberg. 1967. Age determina- tion of mammals from annual layers in teeth and and bones. Nauka, Moskow.

Klingel, H. and U. Klingel. 1966. Tooth development and age determination in the plains zebra (Equus quagga boehmi Matschie). Der Zoologische Garten 33(1/3):34-54.

Laws, R.M. 1962. Age determination of pinnipeds with special reference to growth layers in the teeth. Z. Säugetierk 27:127-146.

Lkhagvasuren, D., H. Ansorge, N. Batsaikhan, R. Samiya, A. Stubbe and M. Stubbe. 2009. Age determination of the Mongolian wild ass (Equus hemionus Pallas, 1775). Mammalian Biology 74, suppl.:17-18.

Lüps, P., M. Graf and A. Kappeler. 1987. Possibilities of the age determination in the badger Meles meles (L.). Jahrb. Naturhist. Mus. Bern 9:185-200 (in German).

Moehlman, P.D. (ed.), (2002). Equids: Zebras, Asses and Horses. Status Survey and Conservation Action Plan. IUCN/SSC Equid Specialist Group. IUCN, Gland, Switzerland and Cambridge, UK 190:62-71.

Moehlman, P.D., N. Shah and C. Feh. 2008. Equus hemionus. In: IUCN (ed.), 2008 IUCN Red List of Threatened Species. <www.iucnredlist.org > Downloaded on 03 December 2012.

Morris, P. 1972. A review of mammalian age determination methods. Mammal Review 2(3):69-104.

Orlov, V.N. 1961. Age variability of the skull in Equus hemionus Pall. Russian Journal of Zoology 40:592-601 (in Russian).

Penzhorn, B.L. 1982. Age determination in cape mountain zebras Equus zebra zebra in the Mountain Zebra National Park. Koedoe 25:89-102.

Reading, R.P., H.M. Mix, B. Lkhagvasuren, C. Feh, D.P. Kane, S. Dulamtseren and S. Enkhbold. 2001. Status and distribution of khulan (Equus hemionus) in Mongolia J. Zool., Lond. 254:381-389.

Sergeant, D.E. 1967. Age Determination of land mammals from annuli. Zeitschrift fuer Saeugetierkunde 32:297-300.

Smuts, G.L. 1974. Age determination in Burchell's zebra (Equus burchelli antiquorum) from the Kruger National Park. J. Sth. Afr. Wildl. Mgmt Ass. 4:103-115.

Stubbe, A., M. Stubbe and N. Batsaijchan. 2007. Morphology, reproduction and mortality of Equus hemionus hemionus in Mongolia. Exploration into the Biological Resources of Mongolia 10:117-132.

Stubbe, A., M. Stubbe, N. Batsaijchan, R. Samja and S. Doržderem. 2005. First result of Wild ass research in the South Aymag/Mongolia in 2003 and 2004. Exploration into the Biological Resources of Mongolia 9:107-120.

Svendsen, E.D. 1997. The professional handbook of the donkey. Whittet Books, Stowmarket.

Wingard, J.R. and P. Zahler. 2006. Silent Steppe: The illegal wildlife trade crises. Mongolian Discussion Papers, East Asia and Pacific Environmentand Social Development Department. World Bank. Washington, D.C.

Submitted: December 3, 2012, Accepted: February 19, 2013 